\title{
Paul Erdös is Seventy
}

Andras Hajnal

Vera T. Sós

HUNGARIAN ACADEMY OF SCIENCES

It is beyond the scope of this short note to describe adequately, for those who do not already know, either the significance of Paul Erdös' own mathematical work, or his enormous influence on contemporary mathematics. He has become something of a legend throughout the whole mathematical world and we can only just add small fragments of our own knowledge to this phenomenon.

To start in a conventional way, here is a short curriculum vitae. He was born in 1913 in Budapest, Hungary. He was a late child of middle class parents. They were both mathematics high school teachers, intelligent and enlightened people. It was soon discovered that Paul was a child prodigy. He could add and multiply six digit numbers when he was six, and beyond his apparent abilities in mathematics, it was his personality that showed, in these early days, the future achievements to come. His parents helped to develop his gifts with understanding and loving care. He was a sensitive child, not tolerating discipline well, with a penetrating interest in all natural sciences, literature, and social problems. He had a strong moral feeling, hating injustice and inequality, and believed in absolute truth-both in science and everyday life. This attitude never changed during his life and also had a strong influence on his mathematical activities.

After some hesitation whether to become a physician, he chose to take up mathematics in 1930 at the University Pázmány Péter in Budapest, where Leopold Fejér held the chair of mathematics. He obtained his first famous result as a first year student: he gave an elementary proof of Chebyshev's theorem. While absorbing mathematical knowledge at a tremendous rate, his truly extroverted personality also became evident. He acquired many friends and soon became the spiritual leader of a small group of enthusiastic young mathematicians, among them Paul Turán, Tibor Gallai, and George Szekeres, just to mention a few. By 1934, he 
graduated and had his $\mathrm{Ph}$. D. accepted as well. With a scholarship he then left for Manchester.

His present life style had already started to take shape in these early years. Mathematics was his main interest, seemingly filling his life entirely, but he maintained his roots and personal contacts by writing innumerable letters and visiting Budapest as often as he could. He started to consider all mathematicians he knew and worked with as his family, taking his responsibilities for them very seriously. We only have a lower estimate, but we think that nowadays he must be writing or answering more than fifteen hundred letters a year, each containing much mathematical information.

The world became more menacing every year and from 1938 on he could no longer visit his home country. He left for the United States and spent the first year at Princeton. His mathematical activity widened and he became more and more prolific. Even the list of subjects he worked with is impressive and unusual. He proved and, equally importantly, conjectured in number theory (both elementary and analytic), interpolation theory, diophantine approximation, theory of series, complex analysis, probability, geometry, algebra, set theory and combinatorics. In quite a few of these subjects his influence and his ideas were decisive.

Erdös could and should be considered as one of the founders of modern combinatorics. In some parts of combinatorics or in combinatorial set theory, it is literally almost impossible to find any good questions not touched by him in one way or other. To date, he has written almost a thousand research papers.

He never took up a permanent job and never settled anywhere. He is still traveling around the world as Professor of the Universe, carrying all his personal possessions in two small shabby suitcases and some additional plastic bags. Along with him travels the invaluable mathematical information he gathers and spreads all over the world. Also traveling with or without him are the innumerable Erdös stories, reflecting his amiable personality.

When Uncle Paul arrives at the Budapest airport nowadays, and gets through visa formalities, a large group of young and not so young mathematicians is waiting for him. After a few steps he starts sorting out presents from the plastic bags, while asking questions about our relatives, discussing health problems of mathematician friends we do not always know (say, from New Guinea), questions about departmental politics intermingled with remarks about the serious situation perhaps in Tanzania or giving partial results on a conjecture of Graham's. We slowly get to the car, while he is still asking questions, addressing Miki as Vera, Vera as Laci, and so on. By the time we get him to his quarters, he immediately makes five phone calls, with the bags partially unpacked. The all-engulfing old atmosphere of mathematics prevails, and we are all deeply involved with the problems he has already suggested. 
It is always fascinating to work with him. He has a fantastic insight, an intense curiosity, and a drive to discover all facts about the subject we are working on. Those who do not know him well, might think he is trying to make a list of all possible theorems. We have seen it many times, that answers to tiny and seemingly unimportant questions which he raised when we were just trying to finish a paper, later turned out to be pertinent to other important problems. Many of them helped to answer questions which were unsolved for years.

Alfréd Rényi, one of his best friends, once said that Paul must have a contract with the devil. Probably this is an impression that true greatness always creates, even about someone who stops to play with every child, and who travels around the world with his mother of ninety, caring about every detail of her comfort and mourning for her many, many years after she died.

It is unbelievable that we are now celebrating his seventieth birthday. $\mathrm{He}$ is one of those people who stay young forever. That is the way it is, and we wish him many happy returns. 